\title{
Is reserpine a human teratogen?
}

\author{
RICHARD M PAULI AND BARBARA J PETTERSEN \\ Departments of Pediatrics and Medical Genetics, University of Wisconsin, Madison, Wisconsin 53705, USA.
}

SUMmaRY A single stillborn female with craniofacial, abdominal, and central nervous system malformations was exposed to reserpine during the first six weeks of gestation. Parallels between the malformations present in this infant and those induced in rats through exposure to reserpine at analogous periods of gestation suggest that reserpine may pose specific risks for malformations in some pregnancies.

Scant information is available concerning possible harmful effects of reserpine in human pregnancy, ${ }^{1}$ although it may be teratogenic in some animals. ${ }^{2} \mathrm{We}$ recently evaluated a stillborn infant with a constellation of malformations extraordinarily similar to those described in exposed rats. ${ }^{2}$

\section{Case report}

This stillborn female was born to healthy 30 year old parents. Her mother had two normal children by a previous marriage. There was no family history of birth defects. Before recognition of this pregnancy, reserpine $(0.50 \mathrm{mg} /$ day $)$ was prescribed for the mother's hypertension and Raynaud's disease. By dating from the last menstrual period, the reserpine exposure was from conceptional day 13 to conceptional day 41 when it was discontinued because the pregnancy was recognised. Other exposures included 10 cigarettes per day and ampicillin late in pregnancy. No fetal problems were recognised before the day of delivery; fetal movement was noted at 16 weeks' gestation and fundal heights remained normal for dates. There was sudden onset of vaginal bleeding at 30 conceptional weeks. Ultrasound showed abruption of the placenta and, in addition, demonstrated multiple congenital malformations in the fetus including an open defect of the abdomen, a large midline fluid filled mass in the brain, and polyhydramnios. Vaginal delivery was elected and the stillborn was delivered in the breech position.

Clinical examination and necropsy evaluation of the infant revealed: weight $1050 \mathrm{~g}$, length $32 \mathrm{~cm}$, and

Received for publication 11 May 1985 Accepted for publication 17 Junc 1985. head circumference $27.5 \mathrm{~cm}$. Craniofacial abnormalities included bilateral cleft lip with deformity of the nose, bilateral cleft palate, and bilateral anophthalmia (figure). There was a marked scoliotic curve in association with a large right sided thoracolumbar open defect without membrane covering (figure). This gastroschisis-like abnormality resulted in eventration of intestine, liver, and lung, the latter made possible because of bilateral diaphragmatic agenesis. The brain contained a cystic mass $6 \mathrm{~cm}$ in diameter which communicated with the ventricles. The placenta and umbilical cord were structurally normal. Both kidneys appeared grossly and microscopically normal, there was no evidence for previous rupture of the amnion, and chromosomal studies by $G$ banding of cells from fetal tissues taken after delivery were normal $(46, \mathrm{XX})$.

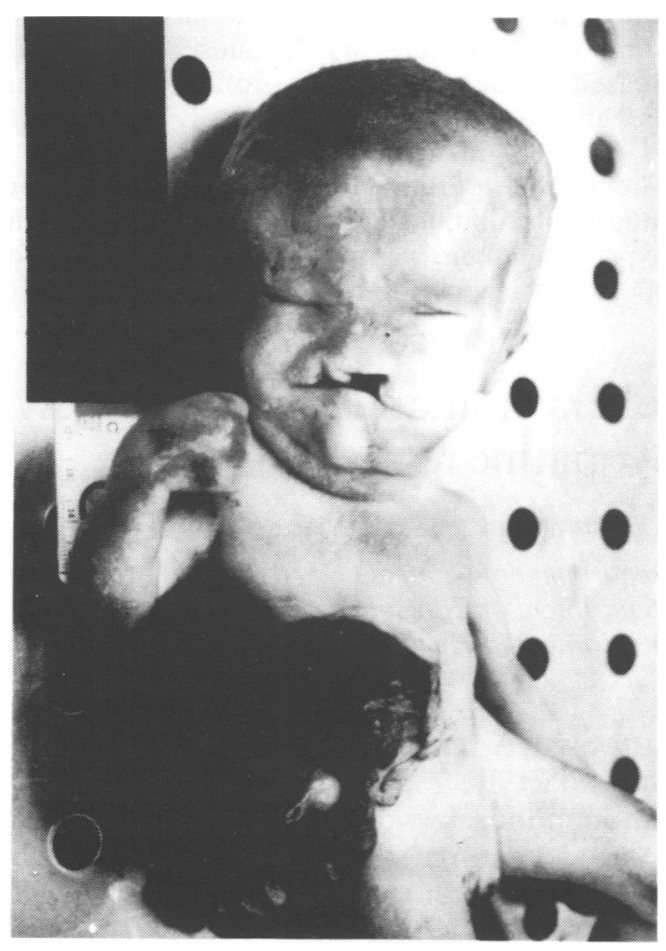

FIGURE Postmortem photograph showing the clinical features described in the text. 


\section{Discussion}

Disorders which could result in a constellation of malformations similar to those seen in this infant include early amnion disruption or short cord sequences, a cytogenetic malformation syndrome, or perhaps Meckel syndrome. No historical or pathological information supports the first, normal cytogenetic studies rule out the second, and the presence of histologically normal kidneys is incompatible with the third. ${ }^{3}$

Heinonen $e a^{1}$ reported a non-significantly raised standardised relative risk for uniform rate malformations of 1.82 for exposures to reserpine and related rauwolfia alkaloids. The list of noted malformations associated with reserpine exposure ${ }^{1}$ includes no examples of a complex similar to that reported here. Similarly, although Sobel ${ }^{4}$ recorded two infant deaths in a series of 15 infants exposed prenatally to reserpine, none had multiple malformations.

In contrast, Goldman and Yakovac ${ }^{2}$ suggested that reserpine exposure (alone or in combination with aspirin) on day 9 or 10 can result in malformations in the rat, including anophthalmia or microphthalmia, thoracoabdominal eventration, cleft lip and palate, central nervous system malformations including encephalocele and cranioschisis, and an increased frequency of late resorptions. Gestational days 9 and 10 in rats are approximately equivalent to days 16 to 24 in humans. ${ }^{5}$

The parallels of timing and of the specific demonstrated malformations are striking. Exposure in the case presented here was at a period analogous to the proposed critical period in rats. The combination of anophthalmia, thoracoabdominal eventration, cleft lip and palate, and central nervous system malformations was present in the rat fetuses and in the human infant described. While in no way proving that the association of reserpine exposure in pregnancy and the multiple malformations seen in this infant are causally related, these parallels do suggest that reserpine exposure may pose specific risks for such multiple malformations in some pregnancies. Additional similar case reports would suggest that this is a 'sentinel case' rather than a fortuitous association.

This infant was initially ascertained through the Wisconsin Stillbirth Service Project supported in part by funding from the Division of Health, Department of Health and Human Services of the State of Wisconsin.

\section{References \\ 1 Heinonen OC, Slone D, Shapiro S. Birth defects and drugs in pregnancy. Littleton, MA: PSG Publishing, 1977:371-6.495. \\ 2 Goldman AS, Yakovac WC. Teratogenic action in rats in reserpine alone and in combination with salicylate and immobi- lization. Proc Soc Exp Biol Med 1965;118:857-62. \\ ${ }^{3}$ Fraser FC, Lytwyn A. Spectrum of anomalies in the Meckel syndrome, or: "Maybe there is a malformation syndrome with at least one constant anomaly". Am J Med Genet 1981;9:67-73. \\ 4 Sobel DE. Fetal damage due to ECT, insulin coma, chlorpro- mazine, or reserpine. Arch Gen Psychiatry 1960;2:606-11. \\ 5 Shepard TH. Catalog of teratogenic agents. 4th ed. Baltimore: Johns Hopkins University Press, 1983:xvii-xix.}

Correspondence and requests for reprints to $\mathrm{Dr}$ Richard M Pauli, Clinical Genetics Center, University of Wisconsin, 1500 Highland Avenue, Madison, Wisconsin 53705, USA.

\title{
Tel Hashomer camptodactyly syndrome: report of a case with myopathic features
}

\author{
M A PATTON*, K D McDERMOT,+ B D.LAKE \\ ${ }^{*}$ Department of Clinical Genetics, Institute of Child Health, 30 Guilford Street, London WC1N 1EH; \\ †Department of Clinical Genetics, Northwick Park Hospital, Watford Road, Harrow, Middlesex; and \\ $\ddagger$ Department of Histopathology, The Hospital for Sick Children, Great Ormond Street, London WC1N 3JH.
}

SUMMARY A child with the Tel Hashomer camptodactyly syndrome is reported. Although muscle weakness and hypoplasia are reported features of this syndrome, further investigation of muscle function has not pre-

Received for publication 26 Octoher 1984 Revised version accepted for publication 21 June 1985. viously been carried out. We report a raised creatine kinase and an abnormal electromyogram and muscle biopsy in this syndrome. The histology of the muscle biopsy shows a wide range fibre diameter in type 1 and type 2 fibres with a relative deficiency of type $2 b$ fibres. It is suggested that this condition may be primarily a myopathy. 